\title{
Carrier flies of multidrug-resistant Escherichia coli as potential dissemination agent in dairy farm environment
}

\author{
Taila dos Santos Alves a , Gustavo Henrique Batista Lara ${ }^{\text {b }}$, Renato Pariz Maluta a , \\ Márcio Garcia Ribeiro ${ }^{\mathrm{b}}$, Domingos da Silva Leite ${ }^{\mathrm{a}, *}$
}

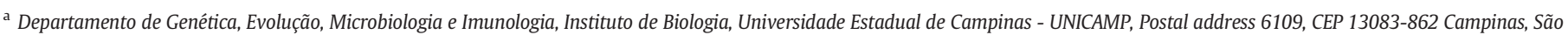
Paulo, Brazil

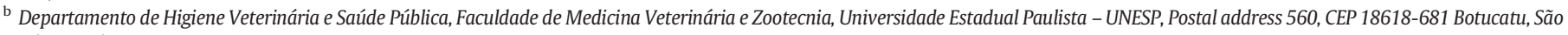
Paulo, Brazil

\section{H I G H L I G H T S}

- Multidrug-resistant Escherichia coli was found on the exoskeleton from flies.

- Antimicrobial resistance determinants were diverse among E. coli clones.

- Flies could facilitate the spreading of antimicrobial resistance genes.

\section{A R T I C L E I N F O}

\section{Article history:}

Received 5 February 2018

Received in revised form 21 March 2018

Accepted 24 March 2018

Available online 2 April 2018

Editor: Jay Gan

\section{Keywords:}

Antibiotic resistance

Mechanical vector

Commensal E. coli

Integron

dfra7

Public health
G R A P H I C A L A B S T R A C T

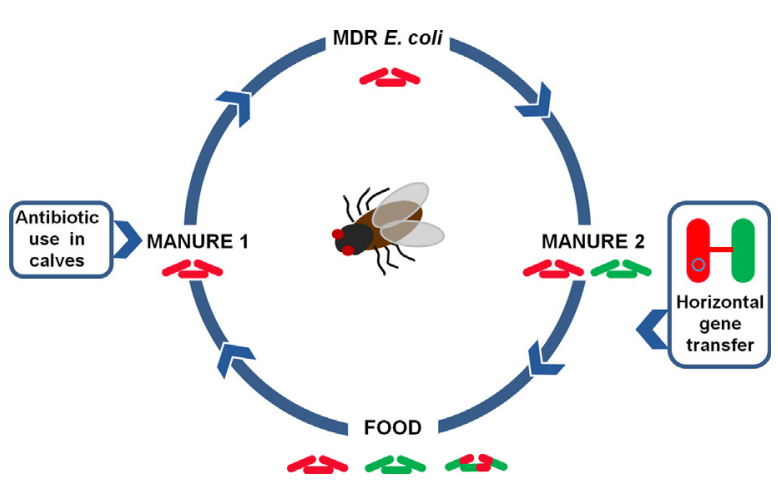

\begin{abstract}
A B S T R A C T
The life cycle of synanthropic flies and their behavior, allows them to serve as mechanical vectors of several pathogens. Given that flies can carry multidrug-resistant (MDR) bacteria, this study aimed to investigate the spread of genes of antimicrobial resistance in Escherichia coli isolated from flies collected in two dairy farms in Brazil. Besides antimicrobial resistance determinants, the presence of virulence genes related to bovine colibacillosis was also assessed. Of 94 flies collected, Musca domestica was the most frequently found in the two farms. We isolated 198 E. coli strains (farm $A=135$ and farm $B=63$ ), and $>30 \%$ were MDR E. coli. We found an association between bla $a_{\text {TEM }}$ and phenotypical resistance to ampicillin, or chloramphenicol, or tetracycline; and bla $a_{\mathrm{CTX}-\mathrm{M}}$ and resistance to cefoperazone. A high frequency (86\%) of phylogenetic group B1 among MDR strains and the lack of association between multidrug resistance and virulence factors suggest that antimicrobial resistance possibly is associated with the commensal bacteria. Clonal relatedness of MDR E. coli performed by Pulsed-Field Gel Electrophoresis showed wide genomic diversity. Different flies can carry clones, but with distinct antimicrobial resistance pattern. Sanger sequencing showed that the same class 1 integron arrangement is displayed by apparently unrelated strains, carried by different flies. Our conjugation results indicate class 1 integron transfer associated with tetracycline resistance. We report for the first time, in Brazil, that MDR E. coli is carried by flies in the milking environment. Therefore, flies can act as carriers for MDR strains and contribute to dissemination routes of antimicrobial resistance.
\end{abstract}

(c) 2018 Elsevier B.V. All rights reserved.

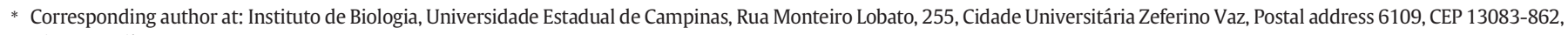
Campinas, Brazil.

E-mail addresses: mgribeiro@fmvz.unesp.br (M.G. Ribeiro), domingos@unicamp.br (D.S. Leite).
} 


\section{Introduction}

Rural, as well as urban environments, enable fly development. This proliferation ability within environments modified by humans is defined as synanthropy. Manure and decaying organic matter are the main food sources for maggot and adult synanthropic flies. Due to the contact with these organic substrates, flies are classically known as carriers of various pathogens (Povolný, 1971). The continuous use of antimicrobials in livestock favors the occurrence of antimicrobial resistance in commensal microorganisms, due to selective pressure (Oliver et al., 2011). So, the close contact between manure and flies assign them as a spreading agent for pathogenic and antimicrobial resistant bacteria.

In the last decade or so, flies have been recognized as vectors of multidrug-resistant bacteria. Marshall et al. (1990) were the first to discuss that flies could represent a dissemination route of antimicrobial resistance genes among the animals of a farm when they sought to understand the natural conditions that contributed to bacterial spread and movement of plasmids in the environment. Later, Rybaříková et al. (2010) found overlapping antimicrobial resistance traits and clones among Escherichia coli isolated from symbovine flies and cattle feces, suggesting the spread of resistant strains from manure by flies.

After detecting $E$. coli clones from flies and calf feces with the same antimicrobial resistance profile, Usui et al. $(2015,2013)$ suggested that flies can disseminate antimicrobial resistance genes not only within farm but also between farms. Similarly, Solà-Ginés et al. (2015) found the same Extended-spectrum $\beta$-lactamase (ESBL)-producing $E$. coli clone isolated from flies within two broiler farms and suggested it may have happened because flies can travel long distances.

In 2016, Schaumburg et al. (2016) investigated antimicrobial resistance in bacteria from rural and urban areas of Münster city in Germany and compared them to isolates from humans. In view of the high similarity of the isolates, they suggested that there could be a common source of transmission of bacteria from flies to humans.

More recently, it was shown that flies played a role in $b a_{\mathrm{NDM}}$ (New Delhi metallo- $\beta$-lactamase) and $\mathrm{mcr}-1$ (plasmid-mediated colistin resistance) gene propagation among chickens and dogs within a farm (Wang et al., 2017).

Here we report that flies can carry multidrug-resistant Escherichia coli on dairy farms in Brazil. We speculate that flies play a considerable role in the spread of antimicrobial resistance in the dairy farm and the environment.

\section{Material and methods}

\subsection{Ethical statement}

The synanthropic flies used in this study were collected in private farms with the owners' permission. Ethical approval is not required.

\subsection{Flies sampling and Escherichia coli isolation}

Flies were collected in the area around calf barns using a sweep net in two dairy farms (A and B) $35 \mathrm{~km}$ apart (Botucatu, São Paulo, Brazil), where bovine breeding is common. The sweep net was disinfected before the use with $10 \%$ bleach for $30 \mathrm{~min}$ and washed between the collect on farm A and farm B. We made collections (on one day in June 2015) in the morning for two hours per farm. We transferred the sets of the flies collected from each capture, introducing sterile tubes into sweep net. Flies were frozen to death at $-10{ }^{\circ} \mathrm{C}$ for $30 \mathrm{~min}$. Thereafter, E. coli from the external surface of flies were cultivated adding $2 \mathrm{~mL}$ of EC broth medium (selective medium for detection of coliforms and $E$. coli) to tubes containing the flies. The tubes were incubated at $37{ }^{\circ} \mathrm{C}$ overnight. Flies were removed and kept in $70 \%$ ethanol for species identification using morphology. A loop from EC broth was placed onto MacConkey agar and five colonies with typical E. coli morphology were selected from each plate and confirmed by biochemical tests.

\subsection{Antimicrobial susceptibility}

We tested Escherichia coli strains by disc diffusion test in accordance with Clinical and Laboratory Standards Institute (CLSI) guidelines (CLSI, 2012a, 2012b) using ampicillin (10 $\mu \mathrm{g})$, amoxicillin/clavulanic acid (30 $\mu \mathrm{g})$, cephalexin $(30 \mu \mathrm{g})$, cefoperazone ( $75 \mu \mathrm{g})$, ceftiofur $(30 \mu \mathrm{g})$, ceftriaxone $(30 \mu \mathrm{g})$, chloramphenicol $(30 \mu \mathrm{g})$, enrofloxacin $(5 \mu \mathrm{g})$, ciprofloxacin $(5 \mu \mathrm{g})$ gentamicin $(10 \mu \mathrm{g})$, sulfamethoxazole/trimethoprim $(25 \mu \mathrm{g})$ and tetracycline $(30 \mu \mathrm{g})$. E. coli ATCC 25922 was used as antimicrobial susceptibility control. Additionally, third-generation cephalosporinresistant $E$. coli was analyzed by double disc synergy using aztreonam (30 $\mu \mathrm{g})$, ceftriaxone ( $30 \mu \mathrm{g})$, cefotaxime (30 $\mu \mathrm{g})$, ceftazidime (30 $\mu \mathrm{g})$ to $20 \mathrm{~mm}$ apart from amoxicillin/clavulanic acid (30 $\mu \mathrm{g})$ disc (Jarlier et al., 1988). Multidrug-resistant strains (MDR, resistant to $\geq 3$ antimicrobial classes) (Magiorakos et al., 2012) were selected for E. coli phylogeny assay and pulsed-field gel electrophoresis.

\subsection{Antimicrobial resistance genes and virulence factors}

Antimicrobial resistance and virulence genes were detected by PCR (Table 1 ). Bacterial DNA was released by boiling and $2 \mu \mathrm{L}$ of supernatant was added to PCR master mix containing $1.5 \mathrm{U}$ Taq polymerase; $1.5 \mu \mathrm{L}$ of $10 \times$ PCR buffer; dNTP mix to $200 \mu \mathrm{M} ; 2 \mathrm{mM} \mathrm{MgCl}_{2} ; 0.5 \mu \mathrm{L}$ of each primer in appropriated concentrations (Table 1 ) and ultrapure sterile water to complete a final volume of $15 \mu \mathrm{L}$.

\subsection{Escherichia coli Phylogeny}

Multidrug-resistant strains were assigned to ECOR phylogenetic groups by PCR (Clermont et al., 2013).

\subsection{Investigation of cassettes genes within class 1 integron}

Sequencing was conducted with $5^{\prime} \mathrm{CS}$ and $3^{\prime} \mathrm{CS}$ primers (Table 1 ) from PCR products purified with AxyPrep PCR Clean Up® Kit (Axygen Biotechnology) using BigDye Terminator v.3.1 Cycle Sequencing Kit and ABI-PRISM 3700 DNA Analyzer (Applied Biosystems, USA). Contigs analyses were done with Sequencher 4.7 software (Gene Codes Corporation) and online tools BLAST (https://blast.ncbi.nlm.nih.gov/Blast.cgi) and ORF Finder (National Center for Biotechnology Information - NCBI) (https://www.ncbi.nlm.nih.gov/orffinder/). For the completeness of sequence structure, we performed linkage PCRs using integron structure genes and sequencing, basing primer walking approach (Table 1).

\subsection{Conjugation assay}

We performed conjugation assays using integron-positive E. coli as donors and azide-resistant E. coli J53 as recipient strain. Experiments were done as described previously by Soufi et al. (2009) with minor modifications. From E. coli growth in Luria-Bertani broth $\left(37{ }^{\circ} \mathrm{C}\right.$ for $18 \mathrm{~h})$, donors and recipient strains were mixed in $1: 10(\mathrm{v} / \mathrm{v})$ proportion, respectively, and incubated at $37^{\circ} \mathrm{C}$ for $18 \mathrm{~h}$. For transconjugants selection, $100 \mu \mathrm{L}$ of the mix culture was streaked onto Mueller Hinton agar plates containing sodium azide and tetracycline and incubated at 37 ${ }^{\circ} \mathrm{C}$. The bacterial growth was verified after $24 \mathrm{~h}, 48 \mathrm{~h}$, and $72 \mathrm{~h}$. To confirm the conjugation, genes harbored in the donor strains were investigated in transconjugant strains by PCR. Plasmids were detected using alkaline lysis (AccuPrep® Plasmid Mini Extraction Kit).

\subsection{PCR-based replicon typing (PBRT)}

Inc./replicon from integron-positives E. coli were assessed with PCRbased replicon typing (Carattoli et al., 2005). 
Table 1

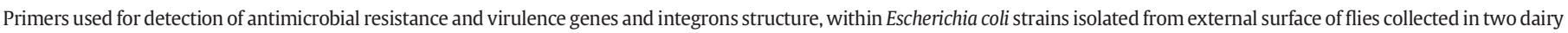
farms in Brazil.

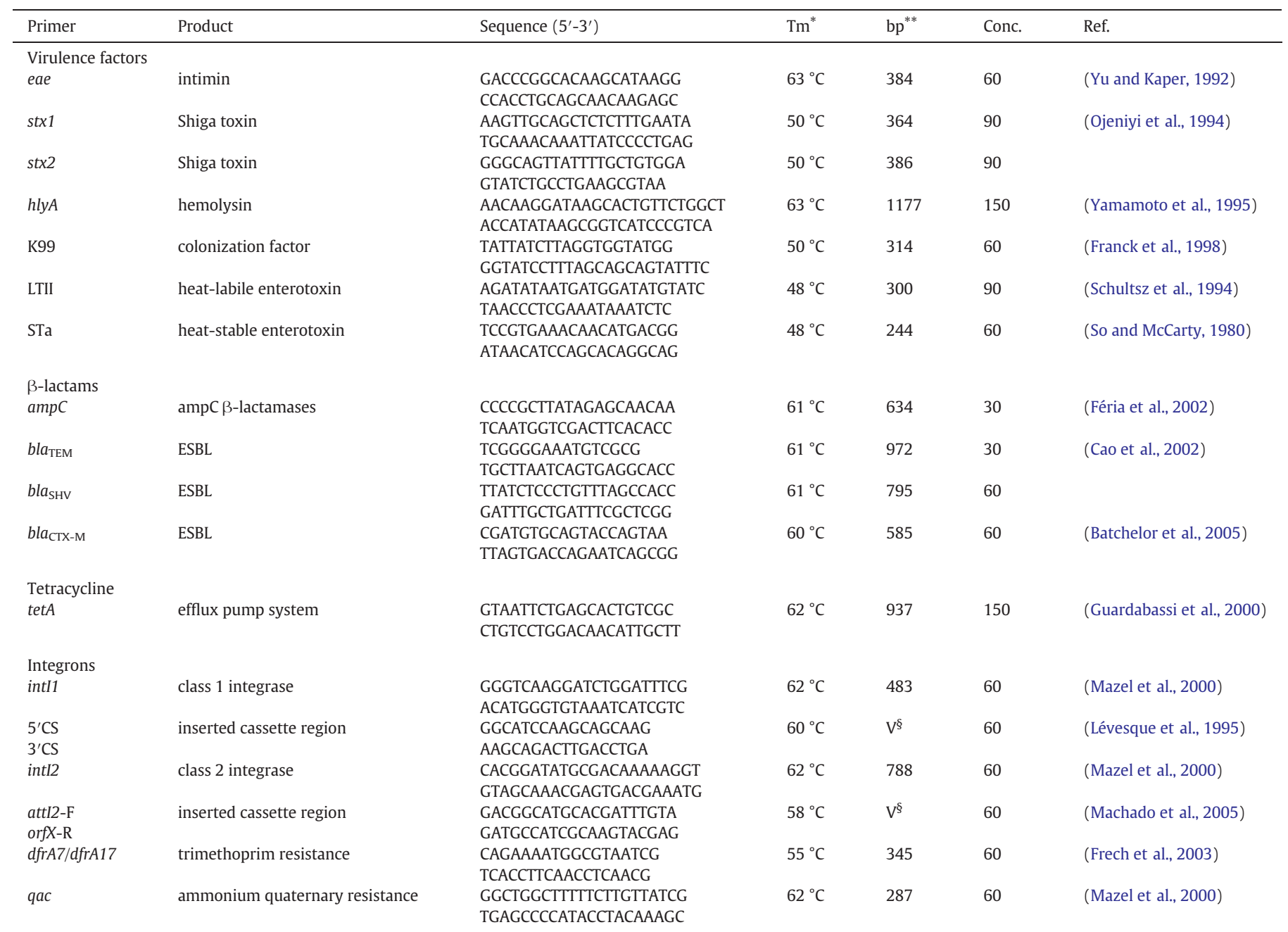

$\mathrm{Tm}^{*}$ : Melting temperature; bp ${ }^{* *}$ : product length; Conc.: primers concentrations (ng/ $\left.\mu \mathrm{L}\right)$; Ref.: Reference; $\mathrm{V}^{\S}$ : variable; ESBL: Extended-spectrum $\beta$-lactamase.

\subsection{Statistical analysis}

Presence or absence of multidrug resistance versus integrons and multidrug resistance versus virulence factors were compared with Fisher's exact test $(p=0.05)$. Resistance phenotypes and resistance genes were analyzed with logistic regression $(p=0.05)$.

\section{Results}

We isolated $198 \mathrm{E}$. coli strains from the external surface of 94 flies (farm A: 135 strains from 57 flies; farm B: 63 strains from 37 flies). Flies most often found on farm A were Musca domestica (Linnaeus, $1758)(n=20)$, Fannia spp. $(n=14)$ and Stomoxys calcitrans (Linnaeus, $1758)(n=10)$. On farm B the most frequently found were $M$. domestica $(n=10)$, Hippelates spp. $(n=7)$, and Acalyptratae $(n=7)$ and Fannia spp. $(n=5)$.

On farm A, antimicrobial resistance genes detected in $E$. coli strains included bla $_{\mathrm{TEM}}(36.3 \% ; 49 / 135)$, tetA $(14.8 \% ; 20 / 135)$, bla CTX-M $_{\text {(1) }}(11.1 \% ; 15 /$ $135)$ and $\operatorname{ampC}(4.4 \% ; 6 / 135)$. Virulence genes found were eae $(2.9 \% ; 4 /$ 135), stx1 (5.2\%; 7/135), hlyA (8.1\%; 11/135), K99 (3.7\%; 5/135), LTII (9.6\%; 13/135), and STa (3.7\%; 5/135). The seven stx1-positive E. coli were isolated from $M$. domestica. On farm B, only five strains harbored ampC, and no strain showed any of the investigated virulence factors.
We found 60 multidrug-resistant $E$. coli from farm A and only two from farm B. Of these MDR E. coli, 52 were assigned to phylogenetic group B1 and eight to group E. The two MDR E. coli from farm B were assigned to the B1 phylogenetic group. Strains from farm A were primarily resistant to ampicillin, amoxicillin/clavulanic acid, tetracycline, sulfamethoxazole/trimethoprim, enrofloxacin, chloramphenicol and ciprofloxacin. On farm B, they are resistant to ampicillin and amoxicillin/clavulanic acid. Phenotypical antimicrobial resistance frequencies are shown in Fig. 1.

Multidrug resistance was associated with the presence of integron $(p=0.0012)$. There was no association between multidrug resistance and eae or hlyA, or LTII or STa $(p>0.05)$. In contrast, K99 was significantly associated with multidrug resistance $(p=0.0158)$, and stx1 gene was associated with multidrug resistance default $(p=0.0171)$. Also, there was association between bla $a_{\text {TEM }}$ and phenotypic resistance to ampicillin $(p=0.0242)$, chloramphenicol ( $p=0.0179)$ or tetracycline $(p=0.0056)$. The $b l a_{\mathrm{CTX}-\mathrm{M}}$ was associated with phenotypical resistance to cefoperazone $(p=0.0458)$. The ampC and tetA genes were not associated with phenotypical resistance to any of the tested antimicrobials.

Class 1 integron structure from eight $E$. coli positives $\left(\right.$ int $11+5^{\prime} \mathrm{CS}-3^{\prime}$ CS) was investigated by PCR and sequenced by primer walking. All strains showed the same integron array (int1-dfrA7-attC-qacE $\Delta 1$ ), with only one dfrA7 cassette gene (GenBank accession no. MF445023, 
MF445024, MF445025, MF445026, MF445027, MF46502, MF465027, MF465028). No E. coli had class 2 integron.

Forty-three MDR E. coli were selected for PFGE typing in accordance with antimicrobial resistance patterns of integron-positive strains and MDR from farm B (Table 2). Thirty-six pulsotypes were generated (Fig. 2), demonstrating wide genomic diversity. Four E. coli (three from farm A and one from farm B) showed 100\% similar fingerprints. These $E$. coli clones were isolated from different sets of flies (MA39, MA9e, and MB2). Moreover, two isolates from Farm A and one from Farm B displayed $>90 \%$ similarity (MA6a, MA2d, and MB1d). We considered clones as the strains with $>90 \%$ of genomic similarity (Fig. 2).

Conjugation experiments conducted with integron-positive E. coli using tetracycline selection showed the transfer of integron genes, $b_{\text {bTX-M }}$ and tetA. PCR results for the transconjugant strains showed that three donor strains transferred all genes. Of these seven $b l a_{\mathrm{TEM}^{-}}$ positive strains, four strains did no transfer $b l a_{\mathrm{TEM}}$ by tetracyclineassociated conjugation. All transconjugants received plasmids.

Additionally, PCR-based replicon typing (PBRT) was performed on all eight integron-positive E. coli. Four strains (MA17a, MA17c, MA17d, MA17e) displayed Inc./replicon groups I, HI1, HI2, FIA, FIB, P, K, F; one strain (MA17b) harbored I, N, FIA, FIB, P, K, F groups; one (MA26a) harbored I, N, HI1, HI2, FIB, P, K, F; one (MA26b) N, HI1, HI2, P, K, and one strain (MA26d) harbored I, N, HI1, HI2, P, K groups.

\section{Discussion}

Our results show different antimicrobial resistance profiles among commensal E. coli clones, carried by different flies (isolates from Chrysomya megacephala, Muscidae, Fannia sp. and, Hippelates sp.), suggest that resistance gene dissemination can be independent of multidrug-resistant clone spread. In contrast, either different individuals of flies or the same individual can carry unrelated strains, but with the same genotype. This is evident in integron-positive E. coli since isolates from different flies showed the same gene array. Furthermore, we find flies from different farms (A or B), carrying MDR E. coli clone (genomic similarity $\geq 90 \%$ ), and harboring distinct antimicrobial resistance markers.

Diversity and similarity of antimicrobial resistance determinants in bacterial clones and unrelated strains can be due to horizontal gene transfer, which is a known process related to antimicrobial genes dissemination between strains (Stokes and Gillings, 2011). Besides, we believe that flies movement can contribute to the spread of a wide range of strains in the environment and offer an advantage in genes transposition.

Previous studies have discussed the role of flies as vectors of antimicrobial resistance bacteria (Blaak et al., 2014; Davari et al., 2010; Literak

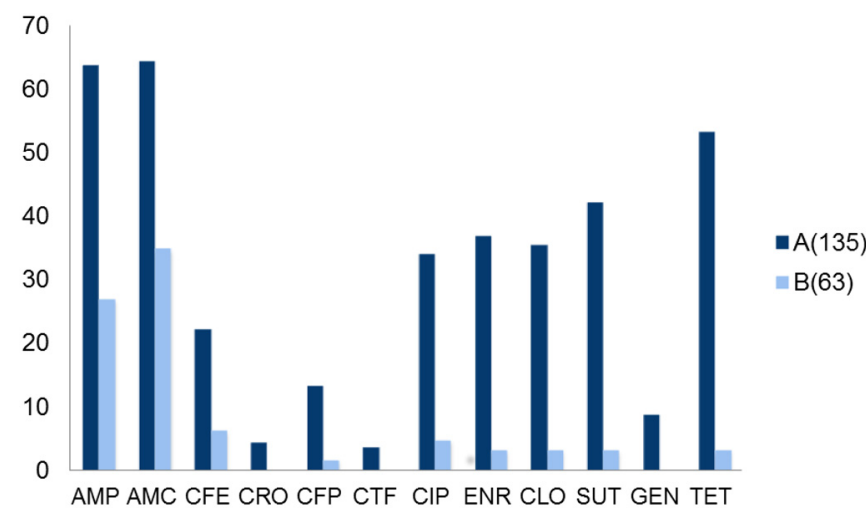

Fig. 1. Antimicrobial resistance frequencies of $E$. coli from flies collected on two dairy farms (A and B), located in Botucatu, SP, Brazil. Farm A with 135 E. coli strains; Farm B with 63 E. coli strains. AMP, ampicillin; AMC, amoxicillin/clavulanic acid; CFE, cefalexin; CRO, ceftriaxone; CFP, cefoperazone; CTF, ceftiofur; CIP, ciprofloxacin; ENR, enrofloxacin; CLO, chloramphenicol; SUT, sulfamethoxazole/trimethoprim; GEN, gentamicin; TET, tetracycline.
Table 2

Multidrug-resistant E. coli groups selected for PFGE assay.

\begin{tabular}{ll}
\hline & Antimicrobial resistance \\
\hline Group I & AMP/AMC/CFE/CFP/CIP/ENR/CLO/SUT/TET \\
Group II & AMP/AMC/CFE/CRO/CFP/CTF/CIP/ENR/SUT/GEN/TET \\
Group III & AMP/AMC/CFE/CIP/ENR/CLO/SUT/TET \\
Group IV & AMP/AMC/CIP/ENR/CLO/SUT/TET \\
Group V & AMP/AMC/CFP/CIP/ENR/CLO/SUT/TET \\
Group VI & AMP/AMC/CFE/CIP/ENR/CLO/SUT/GEN/TET \\
\hline
\end{tabular}

AMP, ampicillin; AMC, amoxicillin/clavulanis acid; CFE, cefalexin; CRO, ceftriaxone; CFP, cefoperazone; CTF, ceftiofur; CIP, ciprofloxacin; ENR, enrofloxacin; CLO, chloramphenicol; SUT, sulfamethoxazole/trimethoprim; GEN, gentamicin; TET, tetraciclyne.

et al., 2009; Liu et al., 2013; Macovei and Zurek, 2006; Marshall et al., 1990; Rahuma et al., 2005; Rybaříková et al., 2010; Schaumburg et al., 2016; Solà-Ginés et al., 2015; Usui et al., 2015, 2013; Von Salviati et al., 2015; Wang, 2013; Wang et al., 2017; Zurek and Ghosh, 2014). In Brazil, Almeida et al. (2014) isolated E. coli, Salmonella spp. and, Staphylococcus spp. from the internal and external surfaces of the flies collected in 30 dairy farms, but they did not find antimicrobial resistant strains. Therefore, our results constitute the first report, from Brazil, of MDR E. coli isolated from flies.

Flies can disseminate bacteria through exoskeletons, regurgitation and excretes (Greenberg, 1973), acting as bioenhanced vector (Kobayashi et al., 1999). Some flies structures facilitate microorganisms carrier (Sarwar, 2015). In this context, Junqueira et al. (2017) said that the microbiome from the external surface of the blowflies and houseflies highlighted their role as mechanical vectors of pathogens due to physical contact. Here, we investigated the role of them as mechanical vectors of MDR E. coli, because external parts of the flies are those in first contact with the contaminated (feces and garbage) or uncontaminated environment (food).

The same MDR E. coli clones isolated from two farms located a long distance from each other indicates regional spreading of clones. This spread may have occurred through several possibilities such as water sources, human contact, fomites, wild animals, and/or flies.

Entomology studies are unclear as to the flight distance of flies, which diverge according to species and stimuli (Jones et al., 1999). Some studies have reported flight distances around 6-7 km (Nazni et al., 2005; Winpisinger et al., 2005). However, it seems possible that longer distances are reached since there are estimates that dispersal of the flies can reach $22 \mathrm{~km}$ or $30 \mathrm{~km}$ (Jones et al., 1999; Nazni et al., 2005), in accordance with data discusses here. Also, we cannot rule out the flies' movement by modes of transport such as cars, buses, milk trucks, delivery trucks, and others.

On examination of the data from farm A, there was not an association between multidrug resistance and virulence presence, except for K99 gene. $>86 \%$ of strains were placed into phylogenetic group B1, known as commensals and most of the E. coli isolated from animals belongs to this group (Tenaillon et al., 2010). These results suggest that multidrug resistance pressure has emerged in commensal strains.

In addition, we found low frequencies of virulence genes in strains from flies on farm A and none from flies on farm B. Moreover, all seven $E$. coli positive for Shiga toxin gene (stx1) were isolated from $M$. domestica, indicating a potential association between Shiga toxinproducing E. coli (STEC) and M. domestica. In this regard, Moriya et al. (1999) were the first to showed STEC transmission by M. domestica, when they investigated an outbreak of the enterohemorrhagic colitis in children in Japan. At that time the authors concluded that flies had served as mechanical vectors.

Escherichia coli from farm A showed more phenotypic and genotypic traits of antimicrobial resistance when compared with strains from farm B. These differences between the two farms can be due to distinct cattle management in each farm. Animals' agglomeration in farm A would possibly facilitate the circulation and maintenance of multidrugresistant and/or pathogenic strains among animals, implying more 


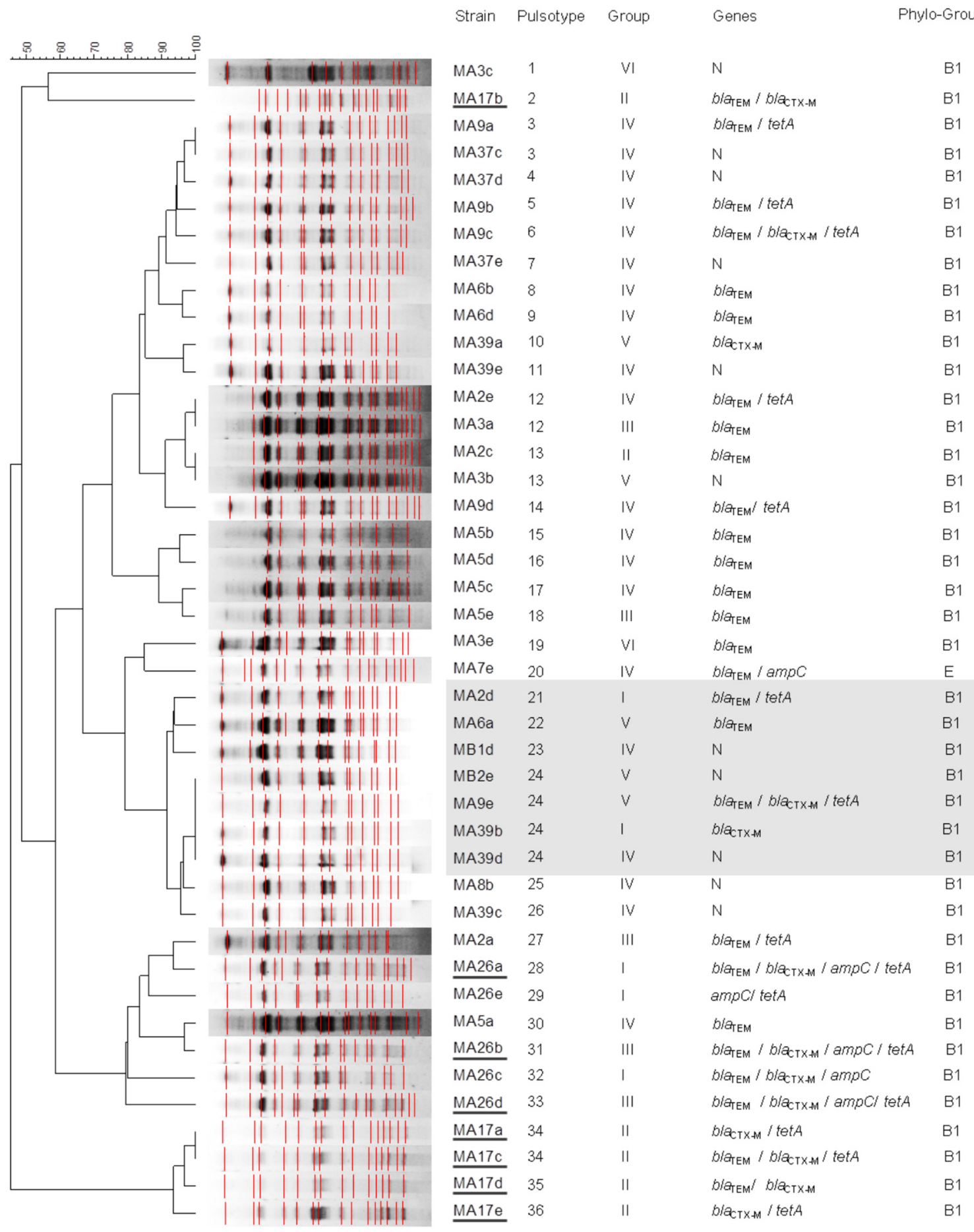

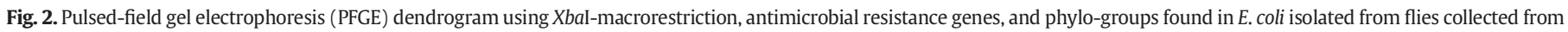

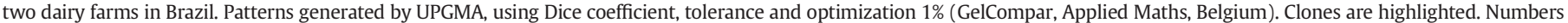
1-36 perform pulsotypes. I to VI perform antimicrobial susceptibility groups. Class 1 integron-positive E. coli are underlined. N: negative. NT: no type.

frequent outbreaks and antibiotic intervention at higher doses. Despite antimicrobial resistance in strains from flies (Fig. 1) has not followed the regular antimicrobial use in calves (ceftiofur, enrofloxacin and gentamicin), these findings suggest that: $\mathrm{i}$ - flies could play an important role in the dissemination of MDR E. coli and pathogenic strains in dairy farms, including the potential introduction of antimicrobial resistant determinants from outside farms; ii - antimicrobial resistance genes could improve fitness advantages. The next step would be to assess antimicrobial resistance and clonal relatedness of $E$. coli isolated from cattle feces and flies.
Integron-positive $E$. coli contained a single gene cassette $d f r A 7$ were isolated from different flies (MA17, M. domestica, and MA26 Fannia sp.). They exhibited different pulsotypes, suggesting that dfrA7 may have regional dissemination. In this regard, Labar et al. (2012) discussed the infrequent arrangement of class 1 integron containing one $d f r A 7$ copy. They found high frequencies of class 1 integrons with single copies of $d f r A 7$ in $E$. coli from healthy humans in Nigeria and Ghana. To our knowledge, there are no reports of dfrA7 gene cassettes in integrons in Brazil from human or animal isolates. 
The results of conjugation assays indicate that antimicrobial selective pressure targeted to commensal $E$. coli and horizontal gene transfer of class 1 integron-associated with tetracycline resistance in strains harboring plasmids known to spread these genes, since replicon groups I, $\mathrm{N}$ e K are associated with the spread of bla $a_{\mathrm{CTX}-\mathrm{M}}$ (Carattoli, 2009) and all integron-positive E. coli harbored IncP related to class 1 integrons and spread of tetracycline resistance genes (Popowska and KrawczykBalska, 2013).

In this context, detection of gene cassettes within integrons, the PFGE fingerprints, and the antimicrobial resistance profile support the dissemination not only of the MDR clones, but also antimicrobial resistance genes, so that gene transfer possibly took place in a horizontal manner and local dissemination of the strains could have been facilitated by flies.

In this study, we provide evidence from Brazil for the inclusion of flies in the dissemination routes of environmental antimicrobial resistance, which is shown to be favored through the flies' synanthropic and communicative behavior.

\section{Conclusions}

Flies seem to play an important role in antimicrobial resistance spread in the dairy farm environment. These vectors can carry antimicrobial resistant strains in the environment acting as MDR bacteria carriers. They could also either insert, take out or maintain antimicrobial resistance in any environment. Importance strains recovered from the external surface of flies should be investigated due to their potential for contact between many surfaces. This intimate contact contributes to strain dissemination and raises a public health concerns.

\section{Acknowledgements}

This study was supported by a scholarship from the Coordenação de Aperfeiçoamento de Pessoal de Nível Superior - CAPES (TSA) and São Paulo Research Foundation-FAPESP [grant no. 2015/15425-2].

The authors are grateful to Mirtis M. G. Ferraz for excellent technical assistance, as well as to Patricia J. Thyssen and Natane S. Purgato for fly species identification and Kayla Wirthwein and Joice Ruggeri for critical English revision.

\section{References}

Almeida, J.L., Giuffrida, R., Andrade, R.P.A., Chaves, M.P., 2014. Muscoid Diptera as potential vectors of bacterial agents on dairy farms in the northern region of Paraná, Brazil Semin. Agrar. 35:3127-3138. https://doi.org/10.5433/1679-0359.2014v35n6p3127.

Batchelor, M., Hopkins, K., Threlfall, E.J., Stallwood, A.D., Davies, Liebana, E., 2005. bla CTX-м genes in clinical Salmonella isolates recovered from humans in England and Wales from 1992 to 2003. Antimicrob. Agents Chemother. 49:1319-1322. https://doi.org/ 10.1128/AAC.49.4.1319.

Blaak, H., Hamidjaja, R.A., Van Hoek, A.H.A.M., De Heer, L., De Roda Husman, A.M., Schets, F.M., 2014. Detection of extended-spectrum beta-lactamase (ESBL)-producing Escherichia coli on flies at poultry farms. Appl. Environ. Microbiol. 80:239-246. https://doi.org/10.1128/AEM.02616-13.

Cao, V., Lambert, T., Nhu, D.Q., Loan, H.K., Hoang, N.K., Arlet, G., Courvalin, P., 2002. Distribution of extended-spectrum $\beta$-lactamases in clinical isolates of Enterobacteriaceae in Vietnam. Antimicrob. Agents Chemother. 46:3739-3743. https://doi.org/10.1128/ AAC.46.12.3739-3743.2002.

Carattoli, A., 2009. Resistance plasmid families in Enterobacteriaceae. Antimicrob. Agents Chemother. 53:2227-2238. https://doi.org/10.1128/AAC.01707-08.

Carattoli, A., Bertini, A., Villa, L., Falbo, V., Hopkins, K.L., Threlfall, E.J., 2005. Identification of plasmids by PCR-based replicon typing. J. Microbiol. Methods 63:219-228. https:// doi.org/10.1016/j.mimet.2005.03.018.

Clermont, O., Christenson, J.K., Denamur, E., Gordon, D.M., 2013. The Clermont Escherichia coli phylo-typing method revisited: improvement of specificity and detection of new phylo-groups. Environ. Microbiol. Rep. 5:58-65. https://doi.org/10.1111/17582229.12019.

CLSI, 2012a. Clinical and Laboratory Standards Institute. Performance Standards for Antimicrobial Disk Susceptibility Tests; Approved Standard.

CLSI, 2012b. Clinical and Laboratory Standards Institute. Performance standards for antimicrobial susceptibility testing.

Davari, B., Kalantar, E., Zahirnia, A., Moosa-Kazemi, S., 2010. Frequency of resistance and susceptible bacteria isolated from houseflies. Iran. J. Arthropod. Borne. Dis. 4, 50-55.
Féria, C., Ferreira, E., Correia, J.D., Gonçalves, J., Caniça, M., 2002. Patterns and mechanisms of resistance to $\beta$-lactams and $\beta$-lactamase. J. Antimicrob. Chemother. 49, 77-85.

Franck, S., Bosworth, B., Moon, H., 1998. Multiplex PCR for Enterotoxigenic, attaching and effacing, and shiga toxin-producing Escherichia coli strains from calves. J. Clin. Microbiol. 36, 1795-1797.

Frech, G., Kehrenberg, C., Schwarz, S., 2003. Resistance phenotypes and genotypes of multiresistant Salmonella enterica subsp. enterica serovar Typhimurium var. Copenhagen isolates from animal sources. J. Antimicrob. Chemother. 51:180-182. https://doi. org/10.1093/jac/dkg058.

Greenberg, B., 1973. Flies and Disease: Biology and Disease Transmission. Vol. 2. Princeton University Press, Princeton, NJ.

Guardabassi, L., Dijkshoorn, L., Collard, J.M., Olsen, J.E., Dalsgaard, A., 2000. Distribution and in-vitro transfer of tetracycline resistance determinants in clinical and aquatic Acinetobacter strains. J. Med. Microbiol. 49:929-936. https://doi.org/10.1099/0022 1317-49-10-929.

Jarlier, V., Nicolas, M., Fournier, G., Philippon, A., 1988. ESBLs conferring transferable resistance to newer $\beta$-lactam agents in Enterobacteriaceae; hospital prevalence and susceptibility patterns. Rev. Infect. Dis. 10, 867-878.

Jones, C.J., Isard, S.A., Cortinas, M.R., 1999. Dispersal of synanthropic Diptera: lessons from the past and technology for the future. Ann. Entomol. Soc. Am. 92 (829-239).

Junqueira, A.C.M., Ratan, A., Acerbi, E., Drautz-Moses, D.I., Premkrishnan, B.N.V., Costea, P.I., Linz, B., Purbojati, R.W., Paulo, D.F., Gaultier, N.E., Subramanian, P., Hasan, N.A Colwell, R.R., Bork, P., Azeredo-Espin, A.M.L., Bryant, D.A., Schuster, S.C., 2017. The microbiomes of blowflies and houseflies as bacterial transmission reservoirs. Sci. Rep. 7:1-15. https://doi.org/10.1038/s41598-017-16353-X.

Kobayashi, M., Sasaki, T., Saito, N., Tamura, K., Suzuki, K., Watanabe, H., Agui, N., 1999 Houseflies: not simple mechanical vectors of enterohemorrhagic Escherichia coli 0157:H7. Am. J. Trop. Med. Hyg. 61:625-629. https://doi.org/10.4269/ ajtmh.1999.61.625.

Labar, A.S., Millman, J.S., Ruebush, E., Opintan, J.A., Bishar, R.A., Aboderin, A.O., Newman, M.J., Lamikanra, A., Okeke, I.N., 2012. Regional dissemination of a trimethoprimresistance gene cassette via a successful transposable element. PLoS One 7:1-10. https://doi.org/10.1371/journal.pone.0038142.

Lévesque, C., Piché, L., Larose, C., Roy, P.H., 1995. PCR mapping of integrons reveals severa novel combinations of resistance genes. 39:185-191. https://doi.org/10.1128/ AAC.39.1.185 Updated.

Literak, I., Dolejska, M., Rybarikova, J., Cizek, A., Strejckova, P., Vyskocilova, M., Friedman, M., Klimes, J., 2009. Highly variable patterns of antimicrobial resistance in commensa Escherichia coli isolates from pigs, sympatric rodents, and flies. Microb. Drug Resist. 15:229-237. https://doi.org/10.1089/mdr.2009.0913.

Liu, Y., Yang, Y., Zhao, F., Fan, X., Zhong, W., Qiao, D., Cao, Y., 2013. Multi-drug resistant gram-negative enteric bacteria isolated from flies at Chengdu airport, China. Southeast Asian J. Trop. Med. Public Health 44, 988-996.

Machado, E., Canto, R., Baquero, F., Gala, J., Coque, T.M., 2005. Integron content of Extended-Spectrum- $\beta$-Lactamase-Producing Escherichia coli strains over 12 years in a single hospital in Madrid. Spain. Antimicrob. Agents Chemother. 49:1823-1829. https://doi.org/10.1128/AAC.49.5.1823.

Macovei, L., Zurek, L., 2006. Ecology of antibiotic resistance genes: characterization of enterococci from houseflies collected in food settings. Appl. Environ. Microbiol. 72: 4028-4035. https://doi.org/10.1128/AEM.00034-06.

Magiorakos, A.P., Srinivasan, A., Carey, R.B., Carmeli, Y., Falagas, M.E., Giske, C.G., Harbarth, S., Hindler, J.F., Kahlmeter, G., Olsson-Liljequist, B., Paterson, D.L., Rice, L.B., Stelling, J., Struelens, M.J., Vatopoulos, A., Weber, J.T., Monnet, D.L., 2012. Multidrug-resistant, extensively drug-resistant and pandrug-resistant bacteria: an international expert proposal for interim standard definitions for acquired resistance. Clin. Microbiol. Infect. 18:268-281. https://doi.org/10.1111/j.1469-0691.2011.03570.x.

Marshall, B., Petrowski, D. Levy, S.B., 1990. Inter- and intraspecies spread of Escherichia coli in a farm environment in the absence of antibiotic usage. Proc. Natl. Acad. Sci. U. S. A. 87:6609-6613. https://doi.org/10.1073/pnas.87.17.6609.

Mazel, D., Dychinco, B., Webb, V., Davies, J., 2000. Antibiotic resistance in the ECOR collection: integrons and identification of a novel aad gene. Antimicrob. Agents Chemother. 44:1568-1574. https://doi.org/10.1128/AAC.44.6.1568-1574.2000 Updated.

Moriya, K., Fujibayashi, T., Yoshihara, T., Matsuda, A., Sumi, N., Umezaki, N., Kurahashi, H., Agui, N., Wada, A., 1999. Verotoxin-producing Escherichia coli 0157: H7 carried by the housefly in Japan. Med. Vet. Entomol. 13, 214-216.

Nazni, W.A., Luke, H., Wan Rozita, W.M., Abdullah, A.G., Sa'diyah, I., Azahari, A.H., Zamree I., Tan, S.B., Lee, H.L., Sofian, M.A., 2005. Determination of the flight range and dispersal of the house fly, Musca domestica (L.) using mark release recapture technique. Trop. Biomed. 22, 53-61.

Ojeniyi, B., Ahrens, P., Meyling, A., 1994. Fimbrial and toxin genes in Escherichia coli and their prevalence in piglets with diarrhoea. The application of colony hybridization assay, polymerase chain reaction and phenotypic assays. J. Vet. Med. 59, 49-59.

Oliver, S.P., Murinda, S.E., Jayarao, B.M., 2011. Impact of antibiotic use in adult dairy cows on antimicrobial resistance of veterinary and human pathogens: a comprehensive review. Foodborne Pathog. Dis. 8:337-355. https://doi.org/10.1089/fpd.2010.0730.

Popowska, M., Krawczyk-Balska, A., 2013. Broad-host-range IncP-1 plasmids and their resistance potential. Front. Microbiol. 4:1-8. https://doi.org/10.3389/fmicb.2013.00044

Povolný, D., 1971. Flies and disease: Ecology, classification and biotic associations. In: G, B. (Ed.), Flies and Disease: Ecology, Classification and Biotic Associations, pp. 17-54 (New Jersey).

Rahuma, N., Ghenghesh, K.S., Ben Aissa, R., Elamaari, A., 2005. Carriage by the housefly (Musca domestica) of multiple-antibiotic-resistant bacteria that are potentially pathogenic to humans, in hospital and other urban environments in Misurata, Libya. Ann. Trop. Med. Parasitol. 99:795-802. https://doi.org/10.1179/136485905X65134.

Rybaříková, J., Dolejská, M., Materna, D., Literák, I., Čížek, A., 2010. Phenotypic and genotypic characteristics of antimicrobial resistant Escherichia coli isolated from 
symbovine flies, cattle and sympatric insectivorous house martins from a farm in the Czech Republic (2006-2007). Res. Vet. Sci. 89:179-183. https://doi.org/10.1016/j. rvsc.2010.02.016.

Sarwar, M., 2015. Insect vectors involving in mechanical transmission of human pathogens for serious diseases. Int. J. Bioinforma. Biomed. Eng. 1, 300-306.

Schaumburg, F., Onwugamba, F.C., Akulenko, R., Peters, G., Mellmann, A., Köck, R., Becker, K., 2016. A geospatial analysis of flies and the spread of antimicrobial resistant bacteria. Int J. Med. Microbiol. 306:566-571. https://doi.org/10.1016/j.ijmm.2016.06.002.

Schultsz, C., Pool, G.J., Van Ketel, R., De Wever, B., Speelman, P., Dankert, J., 1994. Detection of enterotoxigenic Escherichia coli in stool samples by using nonradioactively labeled oligonucleotide DNA probes and PCR. Clin. Microbol. 32, 2393-2397.

So, M., McCarty, B.J., 1980. Nucleotide sequence of the bacterial transposon Tn1681 encoding a heat-stable (ST) toxin and its identification in enterotoxigenic Escherichic coli strains. Proc. Natl. Acad. Sci. USA 77, 4011-4015.

Solà-Ginés, M. González-López J. Cameron-Veas, K, Piedra-Carrasco, N. Cerdà-Cuéllar, M., Migura-Garcia, L., 2015. Houseflies (Musca domestica) as vectors for extendedspectrum $\beta$-lactamase-producing Escherichia coli on Spanish broiler farms. Appl. Environ. Microbiol. 81:3604-3611. https://doi.org/10.1128/AEM.04252-14.

Soufi, L., Abbassi, M.S., Sáenz, Y., Vinué, L., Somalo, S., Zarazaga, M., Abbas, A., Dbaya, R. Khanfir, L., Ben Hassen, A., Hammami, S., Torres, C., 2009. Prevalence and Diversity of Integrons and Associated Resistance Genes in Escherichia coli Isolates from Poultry Meat in Tunisia. Foodborne Pathog. Dis. 6:1067-1073. https://doi.org/10.1089/ fpd.2009.0284.

Stokes, H.W., Gillings, M.R., 2011. Gene flow, mobile genetic elements and the recruitment of antibiotic resistance genes into gram-negative pathogens. FEMS Microbiol. Rev. 35:790-819. https://doi.org/10.1111/j.1574-6976.2011.00273.x.

Tenaillon, O., Skurnik, D., Picard, B., Denamur, E., 2010. The population genetics of commensal Escherichia coli. Nat. Rev. Microbiol. 8:207-217. https://doi.org/10.1038/ nrmicro2298.
Usui, M., Iwasa, T., Fukuda, A., Sato, T., Okubo, T., Tamura, Y., 2013. The role of flies in spreading the extended-Spectrum $\beta$-lactamase gene from cattle. Microb. Drug Resist. 19:415-420. https://doi.org/10.1089/mdr.2012.0251.

Usui, M., Shirakawa, T., Fukuda, A., Tamura, Y., 2015. The role of flies in disseminating plasmids with antimicrobial-resistance genes between farms. Microb. Drug Resist. 21:562-569. https://doi.org/10.1089/mdr.2015.0033.

Von Salviati, C., Laube, H., Guerra, B., Roesler, U., Friese, A., 2015. Emission of ESBL/AmpCproducing Escherichia coli from pig fattening farms to surrounding areas. Vet. Microbiol. 175:77-84. https://doi.org/10.1016/j.vetmic.2014.10.010.

Wang, W., 2013. Houseflies as Potential Vectors for Antibiotic Resistant Bacteria.

Wang, Y., Zhang, R., Li, J., Wu, Z., Yin, W., Schwarz, S., Tyrrell, J.M., Zheng, Y., Wang, S., Shen, Z., Liu, Z., Liu, J., Lei, L., Li, M., Zhang, Q., Wu, C., Zhang, Q., Wu, Y., Walsh, T.R., Shen, J., 2017. Comprehensive resistome analysis reveals the prevalence of NDM and MCR-1 in Chinese poultry production. Nat. Microbiol. 2. https://doi.org/ 10.1038/nmicrobiol.2016.260.

Winpisinger, K.A., Ferketich, A.K., Berry, R.L., Moeschberger, M.L., 2005. Spread of Musca domestica (Diptera: muscidae), from two caged layer facilities to neighboring residences in rural Ohio. J. Med. Entomol. 42:732-738. https://doi.org/10.1603/00222585(2005)042[0732:SOMDDM]2.0.CO;2.

Yamamoto, S., Tsukamoto, T., Kurazono, H., Takeda, Y., Yoshida, O., 1995. Distribution of virulence factors in Escherichia coli isolated from urine of cystitis patient. Microbiol. Immunol. 39, 401-404.

Yu, J., Kaper, J.B., 1992. Cloning and characterization of the eae gene of enterohaemorrhagic Escherichia coli 0157:H7. Mol. Microbiol. 6:411-417. https:// doi.org/10.1111/j.1365-2958.1992.tb01484.x.

Zurek, L., Ghosh, A., 2014. Insects represent a link between food animal farms and the urban environment for antibiotic resistance traits. Appl. Environ. Microbiol. 80: 3562-3567. https://doi.org/10.1128/AEM.00600-14. 